\title{
Delirium is associated with high mortality in older adult patients with acute decompensated heart failure
}

\author{
Misun Pak ${ }^{1 *}$, Masahiko Hara ${ }^{2,3}$, Shoko Miura ${ }^{4}$, Motohide Furuya ${ }^{4}$, Masatake Tamaki ${ }^{3,5}$, Taiji Okada ${ }^{1}$, \\ Nobuhide Watanabe ${ }^{1}$, Akihiro Endo ${ }^{1}$ and Kazuaki Tanabe ${ }^{1}$
}

\begin{abstract}
Background: Delirium is associated with high mortality after cardiac surgery. However, evidence on the epidemiology of delirium in patients with acute decompensated heart failure (ADHF) is limited. This study aimed to assess the incidence and prognostic impact of delirium in patients with ADHF.

Methods: This single-center prospective observational study enrolled 132 consecutive patients with ADHF. We utilized the Diagnostic and Statistical Manual of Mental Disorders, fifth edition and classified the patients into two groups according to the presence or absence of delirium. The primary endpoint was 90-day all-cause mortality. The prognostic impact and risk factors of delirium were evaluated using multivariable Cox and logistic regression analyses, respectively.

Results: The median patient age was 83 (interquartile range, 75-87) years. Approximately 51.5\% were men. Delirium occurred in 36 (27.3\%) patients, and hyperactive delirium was the most frequent type (86.1\%). The 90-day all-cause mortality was higher in the patients with delirium than in those without (21.6\% versus $3.9 \%$, log-rank $p=$ 0.002). Delirium was associated with higher mortality with an adjusted hazard ratio of 6.8 ( $95 \%$ confidence interval, $1.1-42.6, p=0.042)$. The risk factors associated with delirium included advanced age, male sex, higher clinical frailty scale score, and dementia.
\end{abstract}

Conclusions: Delirium was associated with a higher 90-day all-cause mortality in the older adult patients with ADHF. Hyperactive delirium was the most common subtype.

Keywords: Acute decompensated heart failure, Hyperactive delirium, Clinical frailty scale, Dementia

\section{Background}

Delirium is one of the most common mental disorders and is characterized by a disturbance in consciousness, which develops in a short period of time [1]. It is commonly encountered in a variety of clinical settings and conditions, including heart diseases, and advanced age is one of its most known risk factors [2]. The number of

\footnotetext{
* Correspondence: misunpaku0303@yahoo.co.jp

'Department of Cardiology, Shimane University Faculty of Medicine, 89-1 Enya-cho, Izumo, Shimane 693-8501, Japan

Full list of author information is available at the end of the article
}

patients with acute decompensated heart failure (ADHF) has recently been increasing worldwide owing to the increased prevalence of ischemic and non-ischemic heart diseases with aging.

It is important for cardiologists and cardiac surgeons to investigate the epidemiology of delirium and further determine appropriate ways to manage it because this condition is associated with a poor prognosis [3, 4]. Postoperative delirium in the context of cardiac surgery, is associated with prolonged hospital stay as well as higher short- and long-term mortality rates [5-7].

C C The Author(s). 2020 Open Access This article is licensed under a Creative Commons Attribution 4.0 International License, which permits use, sharing, adaptation, distribution and reproduction in any medium or format, as long as you give appropriate credit to the original author(s) and the source, provide a link to the Creative Commons licence, and indicate if changes were made. The images or other third party material in this article are included in the article's Creative Commons licence, unless indicated otherwise in a credit line to the material. If material is not included in the article's Creative Commons licence and your intended use is not permitted by statutory regulation or exceeds the permitted use, you will need to obtain permission directly from the copyright holder. To view a copy of this licence, visit http://creativecommons.org/licenses/by/4.0/. The Creative Commons Public Domain Dedication waiver (http://creativecommons.org/publicdomain/zero/1.0/) applies to the data made available in this article, unless otherwise stated in a credit line to the data. 
However, only a few studies have investigated the relationship between delirium and prognosis in patients with ADHF, with majority of the reported evidence derived from retrospective studies [4-7].

The prognosis of patients with delirium depends on its subtype, which is divided into 3 categories: hyperactive, hypoactive, and mixed [1, 8]. Hypoactive delirium is most commonly observed in patients after cardiac surgery, and the prognosis of these patients is worse than that of patients with hyperactive delirium $[5,9]$. In addition, the incidence of each subtype of delirium differs among underlying clinical conditions, and evidence on the prognosis of each subtype has not been fully established in patients with ADHF [10]. In this context, the objective of this single-center prospective observational study was to investigate the epidemiology of delirium in patients with ADHF, i.e., incidence, prognostic impact of delirium on mortality, and risk factors for delirium.

\section{Methods}

\section{Study population}

This single-center prospective observational study enrolled 132 consecutive adult patients (age, $>18$ years) admitted with ADHF at Shimane University Hospital between January 1 to October 31 in 2018. Herein, we defined ADHF as rapid worsening of heart failure symptoms with a need for hospitalization to manage perfusion failure or severe dyspnea. The patients received standard treatment for heart failure based on their clinical profiles, according to the presence or absence of congestion (described as "wet" vs. "dry" if present vs. absent) and hypoperfusion (described as" cold" vs. "warm" if present vs. absent) as determined in the international guidelines for the management of ADHF [11]. Briefly, bedside physical examination identifies the combination of these options, which includes four clinical phenotypes: warm and wet (well perfused and congested); cold and wet (hypoperfused and congested); cold and dry (hypoperfused without congestion); and warm and dry (compensated, well perfused without congestion) [11]. The decision for hospitalization or treatment strategies was made at the attending physician's discretion. The study protocol complied with the Helsinki Declaration standards and was approved by the institutional review board of Shimane University Hospital. The requirement for written informed consent was waived in this study. The ethical committee reached this recommendation because this study employed an observational design without any pre-specified interventions for the study patients. However, the right to reject the enrolment was guaranteed by the opt-out option in the study protocol, which was relayed to the patients, their family members, or proxy. This study was registered with the University Hospital Medical Information Network Clinical Trials Registry, as accepted by the International Committee of Medical Journal Editors (UMIN000032646).

\section{Diagnosis and treatment of delirium}

The presence of delirium was assessed every day by a doctor or nurse for 14 days after the hospitalization using the Diagnostic and Statistical Manual of Mental Disorders, fifth edition (DSM-5) [1]. The subtypes of delirium were also evaluated using the DSM-5. Hyperactive delirium is described as a disruptive and combative behavior, particularly characterized by agitation, such as restlessness; hypoactive delirium is described as a decreased amount of activity, such as listlessness; and mixed delirium has both features $[1,9]$. Consultation to a psychiatrist was made as necessary. Some patients took oral sedative-hypnotic drugs, such as ramelteon and benzodiazepines. The prescription was completely at the discretion of the attending physician. Ramelteon was used for regulating circadian sleep-wake rhythm, and benzodiazepines were used for the management of anxiety and insomnia associated with ADHF symptoms, but not for the management of delirium. Intravenous sedative medications, such as dexmedetomidine and propofol, were administered for respiratory management to patients who received non-invasive positive pressure ventilation (NIPPV) and those who were intubated. When the patients became delirious, we managed delirium as follows. First, non-pharmacological treatments for delirium were provided to all patients. They included reorientation and environmental interventions, such as proper patient care settings with low-level lighting and minimal noise to avoid sleep interruption at night [12]. When non-pharmacological treatments were insufficient, pharmacological treatments, such as oral antipsychotic drugs, including risperidone, were additionally considered and provided. When agitation was severe, temporal physical restraints were introduced following clinical practice guidelines by the American College of Critical Care Medicine Task Force, but held to a minimum [13]. For example, we introduced restraints only if patients were still interfering with the treatment, such as selfremoval of the infusion route or tracheal tube, even after removal of as much environmental risks causing delirium as possible. Regardless of study enrolment, ethical approval and written informed consent by patients, their family members or proxy were mandatory for restraints and taken at the time of admission as a routine clinical practice at our institution. Every kind of restraint should be discussed by the attending medical staff, including doctors and nurses, before introduction to the patients. Restraints usually started from a bed-fence, with the degree of suppression gradually increasing, such as using mittens, as appropriate. 


\section{Statistical analysis}

The primary endpoint was set as the 90-day all-cause mortality and the secondary endpoint as the cumulative incidence of delirium from the day of admission. The incidence of each subtype of delirium was also recorded. Continuous variables were expressed as medians (interquartile range [IQR, 25th to 75th percentiles]) and categorical variables as absolute numbers (percentages). The study population was classified into two groups according to the presence or absence of delirium during hospitalization to assess the prognostic impact of delirium. Comparison of data between the two groups was performed using the Wilcoxon rank sum test for continuous variables and chi-square test for categorical variables. Kaplan-Meier analysis was employed to estimate the 90-day all-cause mortality and cumulative incidence of delirium with the corresponding 95\% confidence interval (CI). The difference in the 90-day all-cause mortality between the two groups was evaluated using a log-rank test. The prognostic impact of delirium and risk factors associated with delirium were evaluated using univariable and multivariable Cox regression and logistic regression analyses, respectively. Explanatory variables were selected clinically considering previous reports. All statistical analyses were conducted using Microsoft R Open version 3.3.2, and $p$-values of $<0.05$ were considered statistically significant.

\section{Results}

\section{Patient characteristics}

Table 1 shows the patient characteristics on admission. The median age of the study population was 83 (IQR, 75-87) years, and $51.5 \%$ of the patients were men. Approximately $14.4 \%$ of the patients had a history of cerebral infarction, and $27.3 \%$ had dementia. The median clinical frailty scale score was $4(3-5)$ points. In regard to the clinical profiles of heart failure, the warm-wet type was the most frequent at $73.5 \%$. The median brain natriuretic peptide (BNP) level was 601 (331-1264) $\mathrm{pg} / \mathrm{mL}$. Echocardiography showed that the median left ventricular ejection fraction in the entire population was $48 \%(31-60 \%)$. As shown in Table 1 and Fig. 1, a total of 36 (27.3\%; 95\% CI, 19.3-34.5) patients developed delirium within 14 days of their hospital admission. There were some significant differences in the baseline characteristics between the patients with and without delirium (Table 1). The patients with delirium were significantly older and had a higher incidence of previous cerebral infarction and dementia. Clinical frailty scale score, heart rate, and BNP level were significantly higher in patients with delirium compared with patients without delirium.

\section{Clinical course during hospitalization}

Figure 1 and Table 2 show the clinical and treatment information during hospitalization. The days from admission to the onset of delirium was 2 (1-4), and majority of the delirium cases occurred within a week after hospitalization. Most patients developed hyperactive delirium (86.1\%), followed by mixed delirium (8.3\%), and hypoactive delirium (5.6\%). Among the total study population, the percentage of patients who needed intubation and NIPPV was 4.6 and 26.5\%, respectively. Most (78.8\%) patients were treated with diuretics, whereas only approximately $20 \%$ of the patients were treated with inotropes or vasodilators for the management of ADHF. As sedative-hypnotic or antipsychotic drugs, benzodiazepines, ramelteon, risperidone, propofol, and dexmedetomidine were administered to $12.2,28.0,6.8,3.8$, and $15.2 \%$ of the patients, respectively. The median time from admission to discharge was 20 (14-30) days. In the comparisons between the patients with and without delirium, there were significant differences in the treatment strategies; the patients with delirium more frequently received NIPPV, inotropes, and oral and intravenous sedative-hypnotic and antipsychotic drugs, except for benzodiazepines, than did those without delirium. There was no significant difference between the two groups in regard to the duration of hospitalization.

\section{Impact on mortality and risk factors of delirium}

Figure 2 shows the 90-day survival estimates. The 90day mortality was significantly higher in the patients with delirium $(21.6 \%$; 95\% CI, 3.4-36.4) than in those without $(3.9,95 \%$ CI $0.0-8.3)$, at a log-rank $p$-value of 0.002 ; that in the total study population was $8.3 \%(95 \%$ CI, 2.8-13.4). In addition, the multivariable Cox regression analysis revealed that delirium was independently associated with the 90-day all-cause mortality, with a hazard ratio (HR) of 6.8 (95\% CI, 1.1-42.6; $p=0.042$ ) after adjustments of patient backgrounds (Table 3). The multivariable logistic regression analysis demonstrated that older age (adjusted odds ratio [OR], 1.1; 95\% CI, $1.0-1.2 ; p=0.040$ ), male sex (adjusted OR, 3.2; 95\% CI, $1.2-10.1 ; p=0.031$ ), higher clinical frailty scale score (adjusted OR, 2.1; 95\% CI, 1.4-3.4; $p<0.001$ ), and presence of dementia on admission (adjusted OR, 3.3; 95\% CI, 1.1-10.4; $p=0.040$ ) were associated with the development of delirium after hospitalization owing to ADHF.

\section{Discussion}

In the present study, we present several important epidemiological findings on delirium in patients with ADHF in a prospective fashion. The major findings included the following: 1) The incidence of delirium in this study population was $27.3 \%$, and the median time from 
Table 1 Patient characteristics on admission

\begin{tabular}{|c|c|c|c|c|}
\hline & $\begin{array}{l}\text { Overall } \\
n=132\end{array}$ & $\begin{array}{l}\text { Delirium (-) } \\
n=96\end{array}$ & $\begin{array}{l}\text { Delirium (+) } \\
n=36\end{array}$ & $P$-value \\
\hline Age (years) & $83(75-87)$ & $82(75-86)$ & $85(83-91)$ & $<0.001$ \\
\hline Men & $68(51.5)$ & $49(51.0)$ & $19(52.8)$ & 0.859 \\
\hline Body mass index $\left(\mathrm{kg} / \mathrm{m}^{2}\right)$ & $22.3(19.7-24.7)$ & $22.3(19.9-25.0)$ & $22.0(18.8-24.1)$ & 0.284 \\
\hline Hypertension & $101(76.5)$ & $71(74.0)$ & $30(83.3)$ & 0.258 \\
\hline Diabetes mellitus & $49(37.4)$ & $36(37.5)$ & $13(37.1)$ & 0.970 \\
\hline Dyslipidemia & $68(51.5)$ & $51(53.1)$ & $17(47.2)$ & 0.546 \\
\hline Smoking & $50(37.9)$ & 38 (39.6) & $12(33.3)$ & 0.510 \\
\hline Previous cerebral infarction & $19(14.4)$ & $9(9.4)$ & $10(27.8)$ & 0.007 \\
\hline Dementia & $36(27.3)$ & $16(16.7)$ & $20(55.6)$ & $<0.001$ \\
\hline Clinical frailty scale score & $4(3-5)$ & $3(3-4)$ & $5(4-6)$ & $<0.001$ \\
\hline \multicolumn{5}{|l|}{ Underlying heart disease } \\
\hline Ischemic heart disease & $24(18.2)$ & $17(17.7)$ & $7(19.4)$ & 0.818 \\
\hline Severe valvular disease & $37(28.0)$ & $29(30.2)$ & $8(22.2)$ & 0.363 \\
\hline Dilated cardiomyopathy & 18 (13.6) & $13(13.5)$ & $5(13.9)$ & 0.959 \\
\hline \multicolumn{5}{|l|}{ Hemodynamic data } \\
\hline Systolic BP (mmHg) & $138(120-154)$ & $138(119-157)$ & $139(126-153)$ & 0.986 \\
\hline HR (beats per minute) & 78 (60-94) & $74(60-90)$ & $90(74-100)$ & 0.036 \\
\hline \multicolumn{5}{|c|}{ Clinical profile of heart failure } \\
\hline Warm-dry & $24(18.2)$ & $20(20.8)$ & $4(11.1)$ & 0.197 \\
\hline Warm-wet & $97(73.5)$ & $68(70.8)$ & $29(80.6)$ & 0.260 \\
\hline Cold-dry & $1(0.8)$ & $0(0.0)$ & $1(2.8)$ & 0.273 \\
\hline Cold-wet & $10(7.6)$ & $8(8.3)$ & $2(5.6)$ & 0.727 \\
\hline \multicolumn{5}{|l|}{ Medication } \\
\hline Beta-blocker & $50(37.9)$ & $38(39.6)$ & $12(33.3)$ & 0.510 \\
\hline ACEI or ARB & $71(53.8)$ & $55(57.3)$ & $16(44.4)$ & 0.187 \\
\hline Diuretics & $78(59.1)$ & $57(59.4)$ & $21(58.3)$ & 0.914 \\
\hline \multicolumn{5}{|l|}{ Laboratory data } \\
\hline $\mathrm{PaO}_{2}(\mathrm{mmHg})$ & $78.8(59.6-96.8)$ & $78.7(61.2-96.8)$ & $79.1(55.0-95.5)$ & 0.918 \\
\hline $\mathrm{PaCO}_{2}(\mathrm{mmHg})$ & $34.5(30.5-39.8)$ & $34.1(30.9-39.3)$ & $35.2(29.3-40.1)$ & 0.949 \\
\hline $\mathrm{eGFR}\left(\mathrm{mL} / \mathrm{min} / 1.73 \mathrm{~m}^{2}\right)$ & $48.3(27.8-64.3)$ & $47.4(28.6-66.9)$ & $49.9(25.3-57.0)$ & 0.409 \\
\hline BNP level (pg/mL) & $601(331-1264)$ & $513(274-1105)$ & $896(560-1788)$ & 0.002 \\
\hline \multicolumn{5}{|l|}{ Echocardiography } \\
\hline LVEF (\%) & $48(31-60)$ & $50(33-61)$ & $41(30-58)$ & 0.395 \\
\hline
\end{tabular}

Continuous variables are given as medians and interquartile ranges, whereas categorical variables are summarized as exact numbers and percentages. Medication was present if the drug was prescribed regularly at the outpatient visit, regardless of cessation after admission

$A C E I$ Angiotensin-converting enzyme inhibitor, ARB Angiotensin II receptor blocker, BNP Brain natriuretic peptide, BP Blood pressure, eGFR Estimated glomerular filtration rate, $H R$ Heart rate, $L V E F$ Left ventricular ejection fraction, $\mathrm{PaO}_{2}$ Arterial oxygen partial pressure, $\mathrm{PaCO}_{2}$ Arterial carbon dioxide partial pressure

admission to delirium was 2 days; 2) hyperactive delirium was the most common subtype; 3) delirium was associated with increased mortality; and 4) the independent risk factors for delirium in the patients with ADHF were older age, male sex, high clinical frailty scale score, and dementia. Considering the lack of evidence concerning delirium in patients with ADHF, we believe that our prospective observational data bridge the evidence gap in this field and contribute to the advancements in the management of delirium in patients with ADHF.

\section{Incidence of delirium in patients with ADHF}

The incidence of delirium in this study was slightly higher than that in previous retrospective studies of patients with ADHF; the incidence was reported to be 


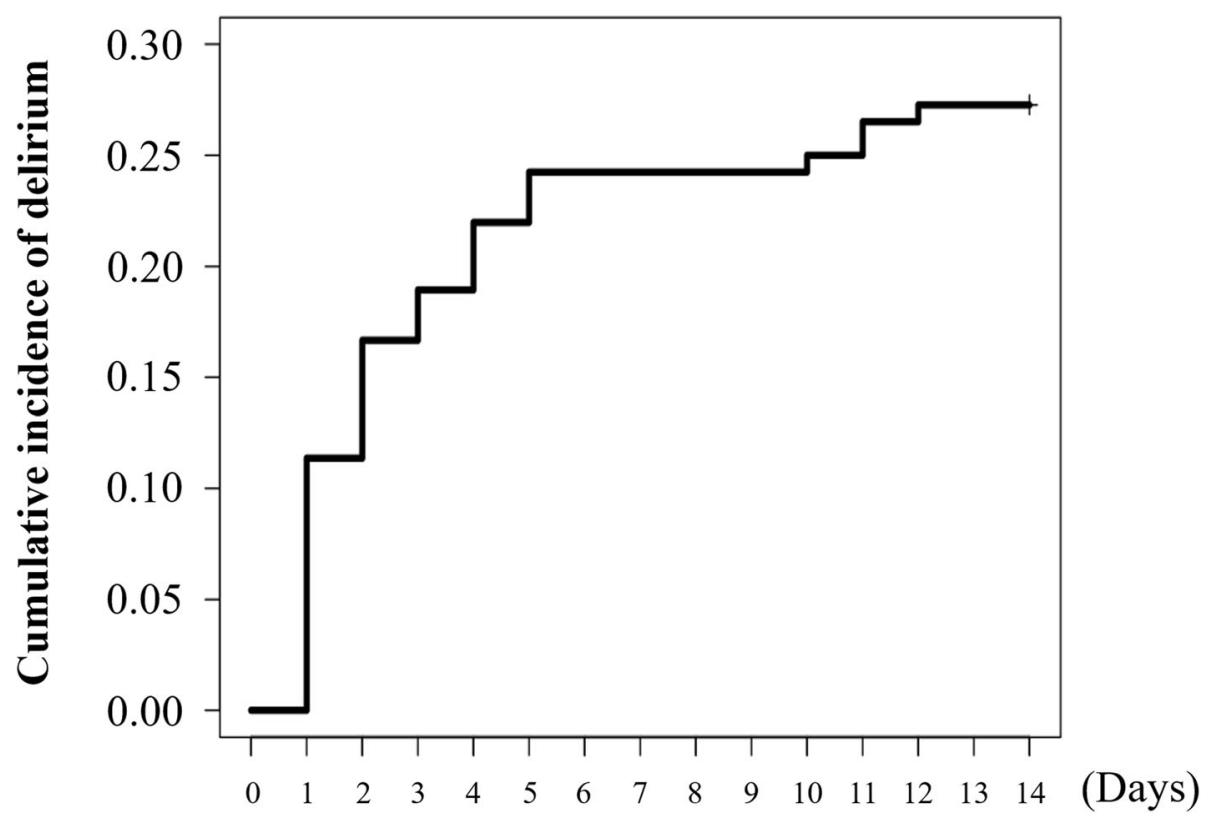

Fig. 1 Cumulative incidence of delirium after hospitalization. The median number of day from admission to the onset of delirium was 2 (1-4). The majority (88.9\%) of delirium cases occurred within a week after hospitalization

$17-23 \%$ during hospitalization $[4,6]$. This can be attributed to the advanced age of our study population compared with that in previous studies because older age is one of the common risk factors of delirium. Herein, we employed the DSM-5 in a prospective fashion. Delirium occurred at the early phase after the onset of ADHF in this study. This is consistent with several previous reports demonstrating that delirium occurred most frequently on the day of the surgery and the next day, and tended to occur until 5 days of surgery [14-16]. However, it is also important to know the possibility of relatively later-phase occurrence of delirium because $4(11.1 \%)$ of 36 patients started to develop delirium after $\geq 10$ days (Fig. 1).

In addition, it is notable that hyperactive delirium was the most common subtype (86.1\%) in the present study, whereas hypoactive delirium was the most common subtype after cardiac surgery in some previous studies $[5,17]$. Because the mechanism and pathophysiology of delirium are poorly understood with several disparate etiologies indicated in previous reports, including hypoxemia, decreased blood supply to the brain, or electrolyte disturbances associated with heart failure, it is difficult to discuss the reason why hyperactive delirium was the most common subtype in this study [7, 18-21]. However, we speculated that impaired circadian rhythm due to insufficient melatonin secretion and expansion of neuroinflammation in patients with ADHF might be associated with the increased incidence of hyperactive delirium [20]. At any rate, we should note that the evaluation of the subtype is recommended for risk stratification because the mortality of patients with hypoactive delirium is higher than that of patients with hyperactive delirium $[1,8,10]$. Although the clinical benefits of medications such as antipsychotics for treating delirium are still controversial due to a lack of qualified evidence, we hope that further understanding about the different incidences of hyperactive and hypoactive delirium due to underlying clinical conditions provides readers with some insights into this field [10, 22, 23].

\section{Prognosis and risk factors for delirium in patients with ADHF}

As the 30-day mortality of ADHF was reported to be $7.0-17.2 \%$, the 90 -day mortality in our study population of $8.4 \%$ is consistent with that reported in previous studies $[24,25]$. We showed that the prognosis of the patients with ADHF who developed delirium was worse than that of those without delirium. Delirium was independently associated with the 90-day all-cause mortality, with an adjusted HR of 6.8 (95\% CI, 1.1-42.6, $p=0.042$ ) in the present study. To the best of our knowledge, there were only two retrospective reports available concerning this topic; Uthamalingam et al. and Honda et al. reported that the adjusted HRs for the presence of delirium in relation to the all-cause mortality were $2.10(95 \%$ CI, $1.53-2.88, p<0.0001)$ at 90 days and $2.38(95 \% \mathrm{CI}$, $1.30-4.35, p=0.005)$ at a median of 335 days in patients with ADHF, respectively $[4,6]$. Our results are consistent with these reports in view of the high risk of delirium in association with mortality; however, the HR was 
Table 2 Clinical and treatment information during hospitalization

\begin{tabular}{|c|c|c|c|c|}
\hline & $\begin{array}{l}\text { Overall } \\
n=132\end{array}$ & $\begin{array}{l}\text { Delirium (-) } \\
n=96\end{array}$ & $\begin{array}{l}\text { Delirium (+) } \\
n=36\end{array}$ & $P$-value \\
\hline \multicolumn{5}{|l|}{ Delirium } \\
\hline Time from admission to delirium (day) & - & - & $2(1-4)$ & - \\
\hline Delirium within a week (\%) & - & - & $32(88.9)$ & - \\
\hline \multicolumn{5}{|l|}{ Subtype of delirium } \\
\hline Hyperactive & - & - & $31(86.1)$ & - \\
\hline Hypoactive & - & - & $2(5.6)$ & - \\
\hline Mixed & - & - & $3(8.3)$ & - \\
\hline \multicolumn{5}{|l|}{ Respirator } \\
\hline Intubation & $6(4.6)$ & $4(4.2)$ & $2(5.6)$ & 0.664 \\
\hline NIPPV & $35(26.5)$ & $21(21.9)$ & $14(38.9)$ & 0.049 \\
\hline \multicolumn{5}{|l|}{ Drug for heart failure } \\
\hline Diuretics & $104(78.8)$ & $73(76.0)$ & $31(86.1)$ & 0.208 \\
\hline Inotrope & $24(18.2)$ & $13(13.5)$ & $11(30.6)$ & 0.024 \\
\hline Vasodilator & $26(19.7)$ & $17(18.5)$ & $9(26.5)$ & 0.325 \\
\hline \multicolumn{5}{|l|}{ Sedative-hypnotic and antipsychotic drugs } \\
\hline \multicolumn{5}{|l|}{ Oral drugs } \\
\hline Benzodiazepines & $16(12.2)$ & $12(12.6)$ & $4(11.1)$ & 1.000 \\
\hline Ramelteon & $37(28.0)$ & $15(15.6)$ & $22(61.1)$ & $<0.001$ \\
\hline Risperidone & $9(6.8)$ & $1(1.0)$ & $8(22.2)$ & $<0.001$ \\
\hline \multicolumn{5}{|l|}{ Intravenous drugs } \\
\hline Propofol & $5(3.8)$ & $1(1.1)$ & $4(11.1)$ & 0.020 \\
\hline Dexmedetomidine & $20(15.2)$ & $6(6.2)$ & $14(38.9)$ & $<0.001$ \\
\hline \multicolumn{5}{|l|}{ Hospitalization } \\
\hline Time from admission to discharge (day) & $20(14-30)$ & $20(15-30)$ & $20(13-31)$ & 0.651 \\
\hline
\end{tabular}

Continuous variables are given as medians and interquartile ranges, whereas categorical variables are summarized as percentages NIPPV Non-invasive positive pressure ventilation

estimated to be higher than that in these two reports. This difference may be attributed to an underestimation of the incidence of delirium associated with the retrospective study design, which then resulted in a lower estimation of the HR.

There are several possible mechanisms underlying the poor prognosis in patients with ADHF complicated with delirium. First, delirium itself implies the presence of poor and severe conditions, such as multiple organ failure due to ADHF [26]. In the present study, the BNP level on admission was higher in the patients with delirium. Although it was adjusted in the multivariable Cox regression analysis, there could be some unmeasured confounders regarding the severity of AHDF. Second, it is possible that treatments for heart failure can be sometimes disturbed by agitated behaviors due to delirium, such as self-extubation, catheter removal, or excessive afterload associated with excessive physical activities, as we showed that hyperactive delirium was the most common subtype in the present study [27]. Last, difficulty in controlling heart failure, such as noncompliance in taking medications and disruption of daily weight monitoring after discharge, might also be associated with the poor outcome [28]. Regarding the risk factors of delirium, advanced age, male sex, high clinical frailty scale score, and dementia were associated with the occurrence of delirium in this study. These risk factors have been proven with sufficient evidence, except for controversies on sex $[2,29,30]$. At any rate, it is notable that advanced age remained as a risk factor even in this advanced-aged study population.

\section{Clinical perspectives}

With the lack of prospective evidence concerning delirium in patients with ADHF, our data contribute to better understanding of delirium in patients with ADHF, and it is noteworthy that hyperactive delirium was the most common subtype observed in the present study. 


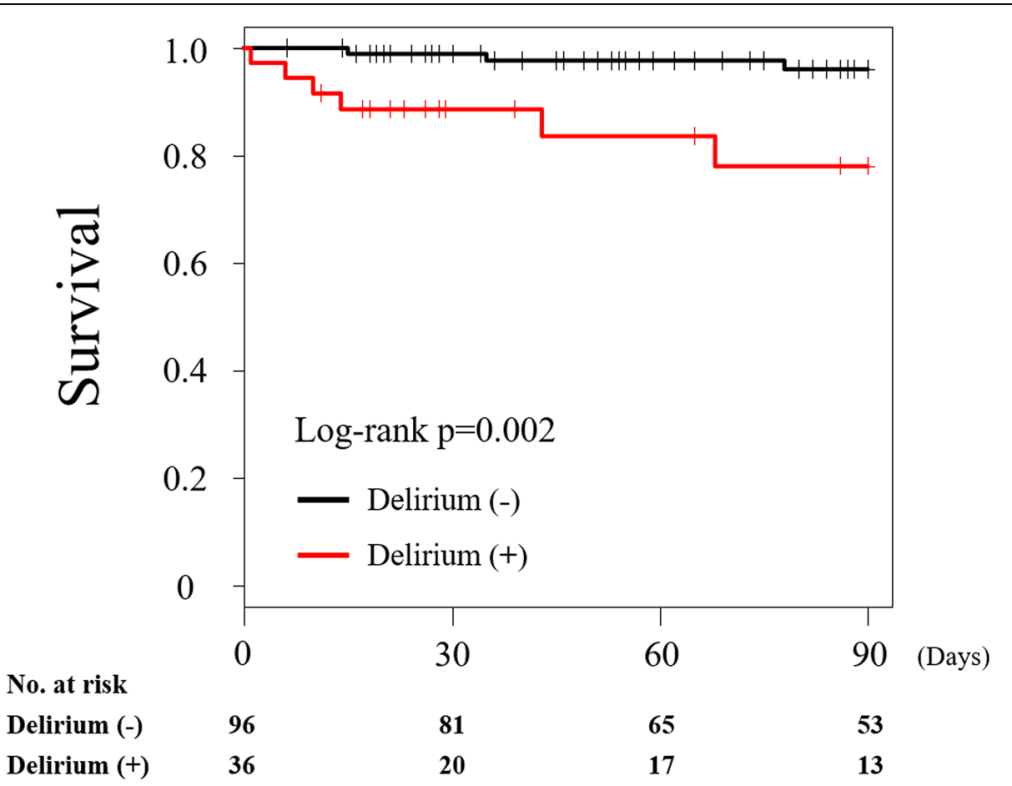

Fig. 2 Kaplan-Meier survival estimate in the patients with and without delirium. The 90-day survival of the patients with ADHF who developed delirium was worse than that of those without delirium (log-rank $p=0.002)$. ADHF, acute decompensated heart failure

Considering that hyperactive delirium was the most common subtype and deleterious patients were more tachycardiac with a tendency to be prescribed less $\beta$ blockers, we speculated that increased autonomic drive, especially of sympathetic systems, on heart function may have deleterious effects and can be a possible therapeutic target in the future [31]. Physicians should consider delirium when treating ADHF, and evaluation of early occurrence of and accurate diagnosis of delirium in relation to the prognosis in patients with ADHF should be strongly considered in future trials.

\section{Limitations}

There are several limitations in the present study, which should be considered when interpreting our results. First, the effect of delirium subtype on mortality could not be assessed in the current study due to the limited number of patients who developed non-hyperactive delirium subtypes. The results of this single-center study should be validated in a multicenter study. Second, we regrettably did not plan to assess the long-term prognosis when we prepared the research protocol, although one of the final goals of medicine is to improve long-

Table 3 Impact of delirium and other clinical indices on the primary and secondary endpoints

\begin{tabular}{|c|c|c|c|c|c|c|}
\hline \multirow[t]{2}{*}{ Primary endpoint (90-day mortality) } & \multicolumn{3}{|c|}{ Univariable } & \multicolumn{3}{|l|}{ Multivariable } \\
\hline & HR & $95 \% \mathrm{Cl}$ & $p$-value & Adjusted HR & $95 \% \mathrm{Cl}$ & $p$-value \\
\hline Age & 1.0 & $0.9-1.1$ & 0.989 & 0.9 & $0.8-1.0$ & 0.081 \\
\hline Male sex & 0.4 & $0.1-1.7$ & 0.240 & 0.5 & $0.1-2.2$ & 0.334 \\
\hline Clinical frailty scale score & 2.0 & $1.3-3.0$ & 0.002 & 1.5 & $0.9-2.5$ & 0.181 \\
\hline Dementia & 6.4 & $1.6-25.7$ & 0.009 & 3.0 & $0.5-20.2$ & 0.251 \\
\hline BNP level & 1.0 & $1.0-1.1$ & 0.673 & 1.0 & $0.9-1.0$ & 0.372 \\
\hline Delirium & 6.8 & $1.7-27.3$ & 0.007 & 6.8 & $1.1-42.6$ & 0.042 \\
\hline \multirow[t]{2}{*}{ Risk factors for delirium } & \multicolumn{3}{|c|}{ Univariable } & \multicolumn{3}{|l|}{ Multivariable } \\
\hline & OR & $95 \% \mathrm{Cl}$ & $p$-value & Adjusted OR & $95 \% \mathrm{Cl}$ & $p$-value \\
\hline Age & 1.1 & $1.0-1.2$ & 0.001 & 1.1 & $1.0-1.2$ & 0.040 \\
\hline Male sex & 1.1 & $0.5-2.3$ & 0.859 & 3.2 & $1.2-10.1$ & 0.031 \\
\hline Clinical frailty scale score & 2.5 & $1.7-3.8$ & $<0.001$ & 2.1 & $1.4-3.4$ & $<0.001$ \\
\hline Dementia & 6.3 & $2.7-14.9$ & $<0.001$ & 3.3 & $1.1-10.4$ & 0.040 \\
\hline BNP level & 1.0 & $1.0-1.1$ & 0.040 & 1.0 & $1.0-1.1$ & 0.339 \\
\hline
\end{tabular}

$B N P$ Brain natriuretic peptide, $C l$ Confidence interval, $H R$ Hazard ratio, OR Odds ratio 
term outcomes, such as survival and quality of life. The reason was based on a scheduled transfer of institution of the primary investigator (M.P). Third, the relationship between delirium and sedative-hypnotic drug use could not be assessed because the decision for administration of such drugs for the patients depended on the individual judgment of each attending physician. More specific proposal for the management of delirium in patients with ADHF could be needed. Fourth, the use of oral or intravenous sedative medications, especially benzodiazepines, is not a normal practice because it results in the development or worsening of delirium later in the course [32, 33]. Lastly, DSM-5 is a much less practical tool, whereas the Confusion Assessment Method is used widely as an efficient and fast tool both for screening and for diagnosis of delirium [3-10]. However, our prospective data remain important, considering the lack of evidence to discuss future perspectives in managing delirium occurring in patients with ADHF.

\section{Conclusions}

Delirium was associated with a higher 90-day all-cause mortality in the patients with ADHF. Hyperactive delirium was the most common subtype according to the DSM-5.

\section{Abbreviations}

ADHF: Acute decompensated heart failure; BNP: Brain natriuretic peptide; Cl: Confidence interval; DSM-5: Diagnostic and Statistical Manual of Mental Disorders, fifth edition; HR: Hazard ratio; IQR: Interquartile range; LVEF: Left ventricular ejection fraction; NIPPV: Non-invasive positive pressure ventilation; OR: Odds ratio

\section{Acknowledgements}

We express our heartfelt gratitude to the Japan Society of Clinical Research for its dedicated support.

\section{Authors' contributions}

MP, MH and MT contributed to the conception and design of the work. MP, $\mathrm{SM}, \mathrm{MF}, \mathrm{MT}, \mathrm{TO}, \mathrm{NW}, \mathrm{AE}$, and KT collected the clinical data. Data analyses were mainly performed by MP and $\mathrm{MH}$, and $\mathrm{MP}, \mathrm{MH}, \mathrm{SM}, \mathrm{MF}, \mathrm{MT}$, TO, NW, $A E$, and $K T$ interpreted these data. MP, MH and MT contributed to the first drafting and $M P, M H, S M, M F, M T, T O, N W, A E$, and $K T$ revising the manuscript critically for important intellectual content. All authors have read and agreed to the contents of the manuscript.

\section{Funding}

None.

\section{Availability of data and materials}

The datasets analyzed during the current study are available from the corresponding author on reasonable request.

\section{Ethics approval and consent to participate}

The study protocol complied with the Helsinki Declaration standards and was approved by the institutional review board of Shimane University Hospital. Written informed consent was substituted by an opt-out fashion according to the recommendation of the ethical committee because this study employed an observational design, which provided patients with no interventions, and patients with delirium could not voluntarily consent by themselves. This study was registered with the University Hospital Medical Information Network Clinical Trials Registry, as accepted by the International Committee of Medical Journal Editors (UMIN000032646).
Consent for publication

Not applicable.

\section{Competing interests}

The authors declare that they have no competing interests.

\section{Author details}

'Department of Cardiology, Shimane University Faculty of Medicine, 89-1 Enya-cho, Izumo, Shimane 693-8501, Japan. ${ }^{2}$ Center for Community-Based Healthcare Research and Education, Shimane University, Izumo, Japan. ${ }^{3}$ Department of Clinical Investigation, Japan Society of Clinical Research, Osaka, Japan. ${ }^{4}$ Department of Psychiatry, Shimane University Faculty of Medicine, Izumo, Japan. ${ }^{5}$ Department of Minimally Invasive Surgical and Medical Oncology, Fukushima Medical University, Fukushima, Japan.

Received: 2 August 2020 Accepted: 23 November 2020

Published online: 03 December 2020

\section{References}

1. American Psychiatric Association. Diagnostic and statistical manual. 5th ed. Washington, DC: APA Press; 2013

2. Zaal IJ, Devlin JW, Peelen LM, Slooter AJC. A systematic review of risk factors for delirium in the ICU. Crit Care Med. 2015;43:40-7.

3. Ogawa M, Izawa KP, Kobayashi SS, Tsuboi Y, Komaki K, Gotake Y, et al. Impact of delirium on postoperative frailty and long term cardiovascular events after cardiac surgery. PLoS One. 2017;12:1-14.

4. Uthamalingam S, Gurm GS, Daley M, Flynn J, Capodilupo R. Usefulness of acute delirium as a predictor of adverse outcomes in patients $>65$ years of age with acute decompensated heart failure. Am J Cardiol. 2011;108:402-8.

5. McPherson JA, Wagner $C E$, Boehm $L M$, Hall JD, Johnson DC, Miller $L R$, et al. Delirium in the cardiovascular ICU: exploring modifiable risk factors. Crit Care Med. 2013;41:405-13.

6. Honda S, Nagai T, Sugano Y, Okada A, Asaumi Y, Aiba T, et al. Prevalence, determinants, and prognostic significance of delirium in patients with acute heart failure. Int J Cardiol. 2016:222:521-7.

7. Lee A, Mu JL, Chiu CH, Gin T, Underwood MJ, Joynt GM. Effect of motor subtypes of delirium in the intensive care unit on fast-track failure after cardiac surgery. J Thorac Cardiovasc Surg. 2018;155:268-75.

8. Stransky M, Schmidt C, Ganslmeier P, Grossmann E, Haneya A, Moritz S, et al. Hypoactive delirium after cardiac surgery as an independent risk factor for prolonged mechanical ventilation. J Cardiothorac Vasc Anesth. 2011;25: 968-74.

9. Meagher D. Motor subtypes of delirium: past, present and future. Int Rev Psychiatry. 2009;21:59-73.

10. O'Keeffe ST. Clinical subtypes of delirium in the elderly. Dementia Geriatr Cognit Disord. 1999;10:380-5.

11. Ponikowski P, Voors AA, Anker SD, Bueno H, Cleland JGF, Coats AJS, et al. 2016 ESC guidelines for the diagnosis and treatment of acute and chronic heart failure. Eur Heart J. 2016;37:2129-200.

12. Fong $T G$, Tulebaev $S R$, Inouye SK. Delirium in elderly adults: diagnosis, prevention and treatment. Nat Rev Neurol. 2009;5:210-520.

13. Barr J, Fraser GL, Puntillo K, Ely EW, Gélinas C, Dasta JF, American College of Critical Care Medicine, et al. Clinical practice guidelines for the management of pain, agitation, and delirium in adult patients in the intensive care unit. Crit Care Med. 2013;41:263-306.

14. Sabol F, Bily B, Artemiou P, Kolesar A, Torok P, Bilecova-Rabajdova M, et al. Incidence and risk factors of delirium in patients after cardiac surgery: modifiable and non-modifiable factors. Cor Vasa. 2015;57:168-75.

15. Robinson TN, Raeburn CD, Tran ZV, Brenner LA, Moss M. Motor subtypes of postoperative delirium in older adults. Arch Surg. 2011;146:295-300.

16. Berger M, Terrando N, Smith SK, Browndyke JN, Newman MF, Mathew JP. Neurocognitive function after cardiac surgery from phenotypes to mechanisms. Anesthesiology. 2018;129:829-51.

17. Mclntyre JS, Charles SC, Anzia DJ. Practice guideline for the treatment of patients with delirium. Am J Psychiatry. 1999;156:1-20.

18. Maldonado JR. Neuropathogenesis of delirium: review of current etiologic theories and common pathways. Am J Geriatr Psychiatry. 2013;21:1190-222.

19. Fong TG, Davis D, Growdon ME, Albuquerque A, Inouye SK. The interface of delirium and dementia in older persons. Lancet Neurol. 2015;14:823-32.

20. Maldonado JR. Delirium pathophysiology: an updated hypothesis of the etiology of acute brain failure. Int J Geriatr Psychiatry. 2018;33:1428-57. 
21. Kotfis K, Szylinska A, Listewnik M, Strzelbicka M, Brykczynski M, Rotter I, et al. Early delirium after cardiac surgery: an analysis of incidence and risk factors in elderly ( $\geq 65$ years) and very elderly ( $\geq 80$ years) patients. Clin Interv Aging. 2018;13:1061-70

22. Burry L, Mehta S, Perreault MM, Luxenberg JS, Siddiqi N, Hutton B, et al. Antipsychotics for treatment of delirium in hospitalised non-ICU patients. Cochrane Database Syst Rev. 2018;6:CD005594.

23. Rooij SE, Schuurmans MJ, Mast RC, Levi M. Clinical subtypes of delirium and their relevance for daily clinical practice: a systematic review. Int I Geriatr Psychiatry. 2005;20:609-15.

24. Estabrooks CA, Midodzi WK, Cummings GG, Ricker KL, Giovannetti P. The impact of hospital nursing characteristics on 30-day mortality. Nurs Res. 2005;54:74-84.

25. Parenica J, Spinar J, Vitovec J, Widimsky P, Linhart A, Fedorco M, et al. Longterm survival following acute heart failure: the Acute Heart Failure Database Main registry (AHEAD Main). Eur J Intern Med. 2013;24:151-60.

26. Siew ED, Fissell WH, Tripp CM, Blume JD, Wilson MD, Clark MJ, et al. Acute kidney injury as a risk factor for delirium and coma during critical illness. Am J Respir Crit Care Med. 2017;195:1597-607.

27. Dubois MJ, Bergeron N, Dumont M, Dial S, Skrobik Y. Delirium in an intensive care unit: a study of risk factors. Intensive Care Med. 2001;27:1297304.

28. Noriega FJ, Vidan MT, Sanchez E, Diaz A, Serra-Rexach JA, Fernández-Avilés $F$, et al. Incidence and impact of delirium on clinical and functional outcomes in older patients hospitalized for acute cardiac diseases. Am Heart J. 2015;170:938-44.

29. Watt J, Tricco AC, Talbot-Hamon C, Rios P, Grudniewicz A, et al. Identifying older adults at risk of delirium following elective surgery: a systematic review and meta-analysis. J Gen Intern Med. 2018;33:500-9.

30. Noimark D. Predicting the onset of delirium in the post-operative patient. Age Ageing. 2009;38:368-73.

31. Zhang DY, Anderson AS. The sympathetic nervous system and heart failure. Cardiol Clin. 2014;32:1-20.

32. Pandharipande P, Shintani A, Peterson J, Pun BT, Wilkinson GR, Dittus RS, et al. Lorazepam is an independent risk factor for transitioning to delirium in intensive care unit patients. Anesthesiology. 2006;104:21-6.

33. Riker RR, Shehabi Y, Bokesch PM, Ceraso D, Wisemandle W, Koura F, SEDCOM (Safety and Efficacy of Dexmedetomidine Compared With Midazolam) Study Group, et al. Dexmedetomidine vs midazolam for sedation of critically ill patients: a randomized trial. JAMA. 2009;301:489-99.

\section{Publisher's Note}

Springer Nature remains neutral with regard to jurisdictional claims in published maps and institutional affiliations.

Ready to submit your research? Choose BMC and benefit from:

- fast, convenient online submission

- thorough peer review by experienced researchers in your field

- rapid publication on acceptance

- support for research data, including large and complex data types

- gold Open Access which fosters wider collaboration and increased citations

- maximum visibility for your research: over $100 \mathrm{M}$ website views per year

At $\mathrm{BMC}$, research is always in progress.

Learn more biomedcentral.com/submissions 